BULLETIN Bulletin hispanique

HISPANIQUE Université Michel de Montaigne Bordeaux

115-1 | 2013

Poésie et société en Espagne : 1650-1750

\title{
Los certámenes poéticos aragoneses del siglo XVII como espacio literario de sociabilidad femenina
}

\author{
$M^{a}$ Carmen Marín Pina
}

\section{(2) OpenEdition}

\section{Journals}

Edición electrónica

URL: http://journals.openedition.org/bulletinhispanique/2405

DOI: 10.4000/bulletinhispanique.2405

ISSN: 1775-3821

Editor

Presses universitaires de Bordeaux

Edición impresa

Fecha de publicación: 1 junio 2013

Paginación: 145-163

ISBN: 978-2-86781-898-1

ISSN: 0007-4640

Referencia electrónica

M ${ }^{a}$ Carmen Marín Pina, « Los certámenes poéticos aragoneses del siglo XVII como espacio literario de sociabilidad femenina », Bulletin hispanique [En línea], 115-1 | 2013, Publicado el 01 junio 2016, consultado el 01 mayo 2019. URL : http://journals.openedition.org/bulletinhispanique/2405; DOI : 10.4000/bulletinhispanique.2405 


\title{
Los certámenes poéticos aragoneses del siglo XVII como espacio literario de sociabilidad femenina ${ }^{1}$
}

\author{
Ma Carmen Marín Pina \\ Universidad de Zaragoza - España
}

Dans la première moitié du XVIIe siècle, en Aragon, un nombre élevé de femmes poètes participe aux différents concours et joutes poétiques qui sont proposés. La poésie devient pour elle un moyen d'assoir prestige et reconnaissance sociale et de participer activement à la vie culturelle et littéraire de l'époque. La célébration de ces rencontres poétiques diminue sensiblement les années suivantes et avec le triomphe du livre de poésie, le panorama se transforme complètement : la voix des poétesses redevient silence.

Mots-clés : écriture féminine, concours de poésie, joutes poétiques, $\mathrm{XVII}{ }^{e}$ siècle, Aragon.

En la primera mitad del siglo XVII se convocan en Aragón diferentes certámenes y justas poéticas a las que concurren un elevado número de mujeres poetas. La poesía se convierte para ellas en un medio de prestigio y reconocimiento social así como de participación activa en la vida cultural y literaria del momento. La celebración de estos encuentros poéticos públicos decae sensiblemente en los años siguientes y con el triunfo del libro de poesía el panorama cambia por completo y la voz de las poetas se silencia de nuevo.

Palabras clave: escritura femenina, certámenes poéticos, justas poéticas, siglo XVII, Aragón.

During the first half of the seventeenth century in Aragon, many women poets took part in the different competitions and poetical jousting then organised. Poetry became for them a means of establishing prestige and social acknowledgement, as well as taking an active part in the cultural and literary of the time. The celebration of these poetical meetings decreased within the following years, and, with the triumph of the poetry book, things completely changed: the poetesses' voices became silence again.

Keywords: women's writing, poetry competitions, poetical jousting, Seventeenth Century, Aragon.

1. Este trabajo forma parte del proyecto de investigación Bieses, financiado por el Ministerio de Ciencia e Innovación (FFI2009-08517).

Bulletin Hispanique, Tome 115, n 1 - juin 2013 - p. 145-163. 
D ara celebrar el matrimonio de Felipe IV con Mariana de Austria, Luis Abarca de Bolea, segundo Marqués de Torres (1617-1653), convocó en Huesca un certamen poético al que concurrieron más de un centenar de poetas de toda España. El licenciado José Félix de Amada, secretario del encuentro, se ocupó de darle forma y en 1650 publicó la Palestra numerosa austriaca. ${ }^{2}$ Avalaban tal iniciativa las inquietudes literarias del Marqués de Torres, mecenas de las letras, poeta y miembro de la academia del conde de Lemos, don Francisco Fernández de Castro, virrey de Aragón, frecuentada por los vates aragoneses más relevantes del momento. Su estrecha amistad con Fr. Jerónimo de San José, cuyo Genio de la historia edita ${ }^{3}$, con Juan de Moncayo y con Andrés de Uztarroz, los tres con buenos contactos en la corte madrileña, así como con otros relevantes poetas aragoneses, entre ellos el oscense Manuel de Salinas, le permitieron llevar a cabo esta empresa y reunir a más de un centenar de participantes. Entre los concursantes figuran cronistas, numerosos doctores y caballeros, religiosos, estudiantes y «hasta las señoras mugeres [...] que empatavan casi sus versos a los de los varones» (Palestra: 17). De ellas quiero ocuparme en concreto y analizar la función de estos certámenes poéticos, con sus respectivas publicaciones, como espacios culturales y literarios también de sociabilidad femenina. Aunque el término «sociabilidad» se acuña más tardíamente, en el siglo de las luces, lo empleo aplicado igualmente al siglo XVII para referirme a las circunstancias y relaciones que propician la participación de las mujeres en la vida social y cultural del momento.

MUJERES Y CIFRAS: CERTÁMENES POÉTICOS ARAGONESES EN LA PRIMERA MITAD DEL SIGLO XVII

De los 127 participantes que responden al llamamiento del cartel de la Palestra, 21 son mujeres, una cifra muy significativa, como advertía José Félix de Amada, pues supone un 16,5\% del total de los concursantes ${ }^{4}$. El porcentaje

2. Palestra numerosa austriaca en la victoriosa ciudad de Huesca al augustíssimo consorcio de los cathólicos Reyes de España don Felipe el Grande y Doña María Ana la inclita. Huesca, Juan Francisco de Larumbe, 1650. Cito por el ejemplar de la Biblioteca Nacional de España R/35396 y he consultado también el ejemplar 2/66981, aunque en la digitalización accesible en la red faltan los folios 80r-83v. Para la contextualización del certamen, véase Oltra Tomás (2000) y Cuevas Subías (2008).

3. A Juan Francisco Andrés de Uztarroz se debe el Elogio al autor del "Genio de la Historia", una semblanza de Fr. Jerónimo de San José que acompaña a la edición de dicha obra en 1651 (Santa Teresa 1957: 219-228). Recoge parte de su producción Latassa y Ortín (2004: item 1293, pp. 194-195). El epistolario intercambiado entre Fr. Gerónimo de San José y Uztarroz da cuenta, sin embargo, de las reticencias que el grupo de amigos tenía hacia la poesía del Marqués de Torres.

4. En este y en los restantes casos, para sacar los porcentajes de los participantes, tengo en cuenta no sólo los poetas premiados y/o editados, sino también los mencionados en las sentencias cuya obra no se publica. Aunque quieren ser precisas, las cuentas son, en último término, aproximativas porque no siempre están claras las atribuciones, hay muchas vacilaciones 
es muy relevante al compararlo con el de otras justas españolas del siglo XVII, donde la presencia femenina es mucho más escasa. Los números hablan por sí solos si se tiene en cuenta que en el conjunto de los certámenes convocados en Madrid entre 1615 y 1692, en total doce con relación en forma de libro impreso o manuscrito, se contabilizan veintiséis mujeres (Baranda 2005); en las valencianas, el recuento no supera la cifra de diez mujeres en catorce certámenes celebrados entre 1592 y 1671 (Mas i Usó 1991: 206-207; 1996: $174-175 ; 1999)^{5}$, lo mismo que en las granadinas en un corpus, en este caso, de siete certámenes organizados entre 1610 y 1691 de los que queda constancia escrita (Osuna 2004) ${ }^{6}$. En las catalanas la participación femenina se incrementa con respecto a los citados, pero no llega nunca a las cifras aragonesas.

En la Palestra el número de mujeres sobrepasa con creces estas cuentas de conjunto, si bien no es nada extraño si se compara con la frecuencia de participantes femeninas en anteriores justas aragonesas. Como se aprecia en el gráfico, entre 1600 y 1650 se celebran en Aragón (Zaragoza, Huesca, Calatayud, Daroca, Tarazona, Alcañiz, Épila) al menos una quincena de justas, de las cuales nos han llegado relaciones manuscritas o impresas de trece cuyos títulos se recogen de forma abreviada en el apéndice ${ }^{7}$. Organizados por la Universidad de Zaragoza, a veces con el concurso de la Ciudad, por diferentes cofradías, por órdenes religiosas o por algún noble local o ciudadano relevante, en Zaragoza, Huesca, Calatayud o Daroca se convocan certámenes para llorar el fallecimiento de Felipe II, de Margarita de Austria, del arzobispo Apaolaza o del príncipe Baltasar Carlos; para celebrar la traslación de las reliquias de san Orencio o de san Ramón Nonat, la beatificación de Santa Teresa, la pureza de la Inmaculada Concepción o el nombramiento de Fray Luis Aliaga (confesor de Felipe III) como Inquisidor General de España; para estimular la devoción a la Sangre de Cristo, a la Virgen del Pilar o a Nuestra Señora de Cogullada o,

onomásticas que pueden inducir fácilmente a error y aparecen también pseudónimos muy genéricos.

5. Hago los cálculos a partir de los materiales ofrecidos en su tesis doctoral (Mas i Usó 1991), donde, junto al comentario de cada justa, recoge los nombres de los participantes. Una ordenación alfabética de los mismos puede verse en su diccionario (Mas i Usó 1999).

6. En el caso granadino, la afluencia de mujeres es más constante en la segunda mitad del siglo XVII que en la primera. En las murcianas la participación es tímida, según se desprende de las justas convocadas entre 1600-1635 y estudiadas por Pérez Gómez y Muñoz Cortés (1958-1959), en las que sólo se registran tres mujeres. Para las catalanas, remito al completo repertorio de Rossich (2005), en el que cita a las premiadas, y al vaciado de certámenes que se está realizando en BIESES.

7. Una descripción de las mismas, con el vaciado de las mujeres participantes, la referencia de sus poemas y las sentencias correspondientes se encuentra en la base de datos BIESES. Para todas ellas, son de obligada consulta los estudios de Aurora Egido recogidos en la bibliografía final y que me eximen de citar los repertorios bibliográficos básicos sobre las justas (Alenda y Mira, Jiménez Catalán, Castro y Calvo, Juan Delgado y José Simón Díaz). Con anterioridad a 1600 , tenemos noticias de tres justas zaragozanas en las que no participan mujeres. Se trata de la justa por la canonización de San Jacinto (1595), el certamen organizado por la Universidad a la muerte de Pedro Cerbuna (1597) (Egido 1983b) y las exequias dispuestas por la ciudad de Zaragoza a la muerte de Felipe II (1599). 
como la Palestra, para festejar las bodas de Felipe IV con Mariana de Austria. Este tipo de citas poéticas tienen un carácter público y están abiertas, por tanto, a todo tipo de participantes siempre que respeten las normas fijadas en el cartel. La poesía emanada de estas celebraciones es, lógicamente, poco intimista y muy sujeta al momento y al motivo de la celebración.

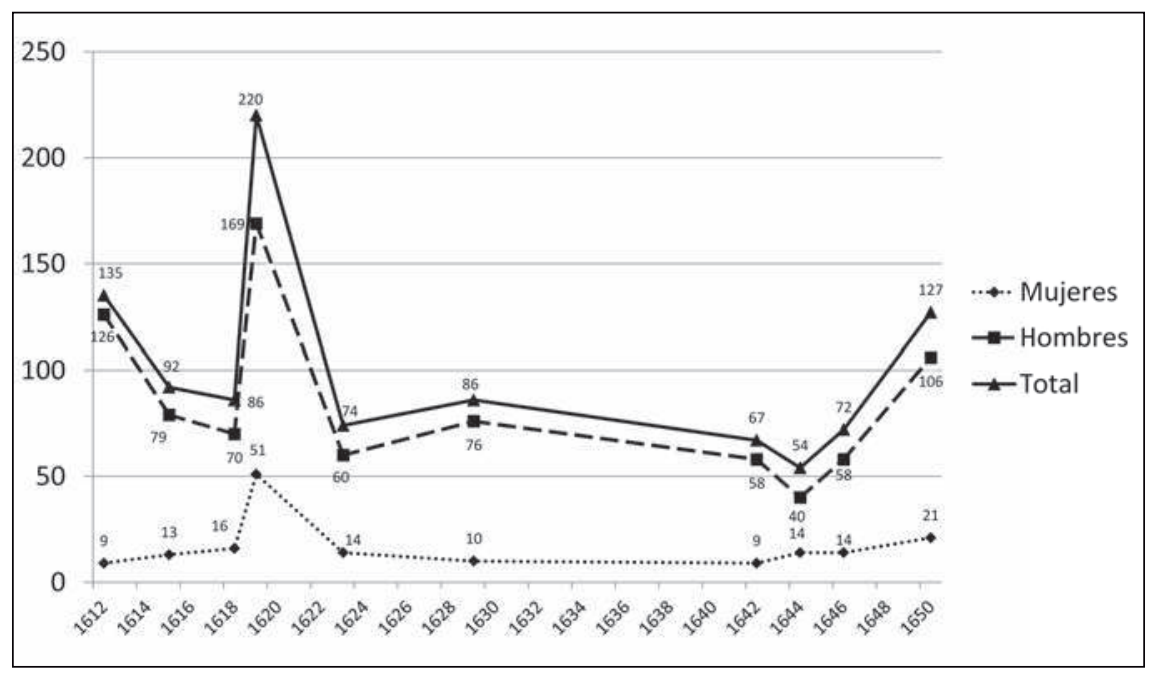

Participantes en las justas aragonesas: 1600-1650

En este medio siglo de certámenes aragoneses, concurren 157 mujeres, de las cuales 13 repiten en diferentes justas. En el gráfico se observa cómo la participación femenina se incrementa progresivamente entre 1612 y 1623 , siendo el momento culminante 1619 , fecha en la que se convocan, al menos, dos certámenes de los que dan cuenta las obras de Luis Díez de Aux, Compendio de las fiestas que ha celebrado la imperial ciudad de Çaragoça por aver promovido la Magestad Cathólica del Rey nuestro señor Filipo Tercero de Castilla y segundo de Aragón, al Illustríssimo señor don Fray Luis de Aliaga su confessor, y de su Real Consejo de Estado, en el oficio y cargo supremo de Inquisidor General de España, y de Sancho Zapata, Iusta poética en defensa de la pureça de la Inmaculada Conçepcion de la Virgen Sanctissima. Sobre un total de 220 participantes, el número de mujeres en estas dos justas de 1619 asciende a 51, lo que supone un $23,18 \%$ de intervención femenina. Como se percibe en la estadística, entre 1618-1619 los hombres pasan de 70 a 169 y las mujeres de 16 a 51; es decir, los hombres duplican, pero las mujeres triplican.

Posteriormente, entre 1623 y 1642 hay un descenso y vuelve a advertirse un repunte entre 1642 y 1650. En líneas generales lo que se observa en estos años es una tendencia de participación femenina paralela a la masculina; si los hombres aumentan su concurrencia, las mujeres también. Sólo hay una excepción en 1615, con un descenso de la participación de los varones con respecto de la justa anterior (de 126 bajan a 79) y una subida de las versificadoras (de 9 a 
13). Entre 1642-1644 desciende de nuevo el número de varones (58 frente 40), pero aumenta la presencia de las mujeres ( 9 frente a 14). El crecimiento de los participantes se debe a las féminas. Entre 1644-1646 no hay incremento entre las mujeres. En líneas generales puede decirse que las mujeres que acuden a estos certámenes se estabilizan hasta 1650 , año en el que se aprecia de nuevo un leve repunte.

Las cifras revelan un interés de las mujeres por la poesía en un momento de clara efervescencia poética en toda España (Sánchez 1960: 13) y en concreto en Aragón, donde existe una larga tradición en la edición impresa de poesía, especialmente de cancioneros y romanceros (Egido 1986; Pérez Lasheras 2010). La intervención de las mujeres en este tipo de certámenes se veía con buenos ojos y padres, maridos y amigos las animaban a concursar y, si era preciso, les buscaban versos sobre los que estampar luego su nombre para inmortalizarlas en el libro del certamen. Es lo que sucede en la justa de Gerona patrocinada por el caballero oscense don Martín de Agullana por la canonización de San Ignacio y San Francisco Javier (1623), cuyas tres hijas, Francisca, Magdalena y Orosia de trece, diez y siete años, respectivamente, firman poemas a la devoción que otros hicieron por ellas (Riquer 1983: 563). En las sentencias de las justas aragonesas se escuchan quejas de falsas autorías femeninas, de versos comprados o tomados prestados para "conquistar renombre». Las denuncias más explícitas las hace Juan Bautista Felices de Cáceres en el Certamen poético por la cofradía de la sangre de Christo (1623) y en la Justa poética por la Virgen Santíssima del Pilar (1629), y revelan la importancia que había alcanzado la poesía como instrumento de prestigio y distinción social, a la vez que alertan de una práctica fraudulenta que en el fondo cuestiona y siembra dudas sobre la autenticidad de las atribuciones femeninas 8 .

$\mathrm{Al}$ margen de estos casos, lo cierto es que existe una respuesta creciente y entusiasta de las mujeres a este tipo de convocatorias que quizá se explique a la luz de la revalorización de la figura y la obra de Teresa de Ávila, a finales del siglo XVI, gracias a la edición Fray Luis de León (Baranda 2005: 94). El modelo o el ejemplo teresiano sin duda animó a las mujeres a escribir y a publicar, en este caso a "hacer públicos» sus versos a través de la lectura oral y/o la letra impresa. Las justas celebradas en toda España con motivo de la beatificación de Teresa de Jesús cuentan con una nutrida representación femenina y ayudan a construir una identidad colectiva o grupal que respalda su propia escritura en un espacio o marco compartido con los poetas, sirviendo de acicate para animar a otras mujeres a participar en posteriores certámenes ${ }^{9}$. Es lo que sucede

8. «Con las damas me enojo / que se buscan poetas, satisfechas / ya de un çurdo, ya de un coxo / que hazer es imposible cosa a derechas, / tan mal sale prestada / toda poesía, cual muger o espada» (Felices de Cáceres, Certamen poético por la cofradia de la sangre de Christo, p. 494). En el punto de mira está Doña Juana Bardaxí (p. 494), pero tampoco se libran Isabel Moreno (p. 453) e Isabel de Aragón (p. 508).

9. Nieves Baranda (2005: 95) estima que la participación de mujeres en las justas llega a su máxima concentración en 1615, "precisamente debido a las justas celebradas a la beatificación de Santa Teresa-, que se mantienen en los ańos veinte y treinta y que cae muy notablemente en 
en Aragón, donde el certamen organizado y sufragado por el doctor Francisco Miravete, lugarteniente de la corte de Justicia de Aragón y escritor, cuenta con una alta participación femenina (en total un 16,46 \%) que desde entonces se mantendrá y acrecentará.

En esta primera mitad del siglo XVII, las mujeres que concurren a estas justas aragonesas, seglares o religiosas, pertenecen a las clases altas (alta o baja nobleza) ${ }^{10}$ y, preferentemente, a la clase ciudadana, a un grupo social privilegiado que monopolizaba el poder urbano, los cargos públicos de la sociedad aragonesa ${ }^{11}$. A la llamada de estas justas se presentan también, como luego en la Palestra, mujeres de otros puntos de la Península, en concreto de Navarra, Valencia y de Madrid. Al certamen bilbilitano por la Inmaculada Concepción (1619), de la corte madrileña llegan, por ejemplo, los versos de María Cáncer de Oropesa con una carta en verso dirigida al organizador, el caballero Sancho Zapata, que por, ser de mujer y en verso, el que fuera diputado del reino de Aragón en 1591 y poeta publica (pp. 197-198) ${ }^{12}$. Por ella sabemos que el cartel del torneo corrió entre los poetas de la corte y que se rumoreaba que los premios estaban dados.

En el círculo en el que se mueven estas mujeres con formación, lectoras de versos y parte del amplio público que sustenta el mercado, la poesía como tal ocupa un lugar, tiene una función de afirmación o reafirmación personal, de pertenencia a un grupo, de propaganda política y religiosa, de promoción social, que quieren también compartir. Muchas de ellas cuentan con una red de conexiones personales que las vinculan al mundo cultural aragonés y las respalda

la segunda mitad». Para las justas por la Beatificación (1614) y Canonización (1622) de Teresa de Jesús, véase la bibliografía recogida en BIESES, entre otros, los trabajos de Romera Castillo (1982) y Elizalde (1984). En las catalanas, recopiladas por José Dalmau, Relación de la solemnidad con que se han celebrado en la ciudad de Barcelona las fiestas a la beatificación de la Madre S. Teresa de Jesús..., Barcelona, 1615, son nueve las mujeres que concurren y una de ellas es Sor Teresa del Calvario, una capuchina de Zaragoza, que, en cambio, no acude al torneo aragonés.

10. Entre ellas figura, por ejemplo, Ana Martínez de Luna, condesa de Morata y esposa del virrey Miguel Martínez de Luna, que acude al Certamen poetico a las fiestas de la translación de la reliquia de San Ramon Nonat (1618), lo mismo que Francisca de Bolea, condesa de Fuentes. María Clemente, señora de Quinto y esposa de Juan de Funes, se presenta al certamen que celebra el nombramiento de Aliaga como Inquisidor General de España (1619); María de Pedroso y Andrade, señora de Villel, a la justa en defensa de la Inmaculada Concepción (1619), e Isabel Sanz de Latrás, condesa de Contamina, a la contienda por el fallecimiento de Baltasar Carlos (1646).

11. En ese momento se está librando una lucha entre la élite dirigente aragonesa, pues la nobleza aspira a obtener puestos de responsabilidad en la administración de la monarquía, puestos copados por el grupo ciudadano. Un panorama general sobre la sociedad aragonesa del momento brinda Salas Auséns (1998), Mateos Royo (2001) y, especialmente, Serrano Martín (2010) con comentarios precisos sobre el sentido político y social de todas estas fiestas.

12. Véase Latassa (2004: item 848). No he logrado encontrar referencias sobre María Cáncer de Oropesa. En su edición de las obras de Jerónimo de Cáncer y Velasco, Solera López (2005) sugiere la posibilidad de que pudieran pertenecer al mismo linaje. Lo cierto es que ambos frecuentaron el ámbito palaciego y en la carta, además de nombrarse dama de la reina de Portugal, se jacta de haber visto el monarca su poema (p. 198). No era además la primera vez que enviaba sus versos a tierras aragonesas, pues un año antes, en 1618, había participado en el certamen poético por la traslación de las reliquias de San Ramón Nonat. 
a la hora de coger la pluma. A través de esta red de relaciones personales, a veces de parentesco y otras de amistad, estas aficionadas a la poesía entran en el juego y, por iniciativa o por invitación, escriben versos, irrumpiendo en ocasiones en espacios culturales tradicionalmente vedados para ellas como es la Universidad, pues muchos de estos certámenes aragoneses los organiza la Universidad y en sus claustros se leen los versos y las sentencias (Egido 1983). Ello es posible porque se trata de convocatorias públicas y, por tanto, abiertas para todo aquel que sepa versificar y logre ajustarse a las normas del certamen. Las concursantes no sólo compiten con los socorridos sonetos y romances demandados, sino que entran en la lid con canciones a imitación de las de Garcilaso y Petrarca o con rimas encadenadas según los modelos del Arte Poética de Rengifo (Egido 1978-1980), lo que exige por su parte un conocimiento de los modelos y un adiestramiento en el noble arte de contar versos. Para la inmensa mayoría de estas mujeres, la poesía es un mero recreo o pasatiempo, pero también una vía excepcional e irrepetible para aproximarse puntualmente al mundo cultural y literario del momento y, sólo en contadas excepciones, un medio para iniciar una carrera literaria o para confirmarla. Para ellas la poesía es un adorno, una habilidad bien vista, un distintivo social en un momento en el que lo literario está alcanzando cierto prestigio social, pero nunca un oficio.

De estas 171 mujeres que en la primera mitad de siglo acuden a los certámenes aragoneses, muy pocas son poetas y cuentan con corpus poético. De hecho contadas son las mujeres de este censo que repiten en los diferentes certámenes. Tan sólo poco más de una docena reaparecen en dos justas o, como mucho, en tres y, en cualquiera de los casos, la cosecha de sus versos es, en general, pobre en cantidad y en calidad. Su práctica poética es, por tanto, circunstancial, ocasional y pocas merecen realmente el nombre de poetas, al igual que muchos de los varones participantes. Como ellos, el amateurismo de estas mujeres que ofician como poetas merece un reconocimiento, el mismo que Lupercio Leonardo de Argensola hiciera en uno de sus discursos a una academia zaragozana a aquellos nobles que escriben sin pretender el nombre de poeta, «sabiendo que un poeta mediano es de ningún precio, y un poeta grande pasa un siglo antes que se ve, porque el ingenio y el estudio poético han de concurrir muchas veces [...] Mas no por esto deben abstenerse de hacer algunos versos que ejercitan el ingenio ni dejar de entender los poetas, porque, como al principio dije, enseñan deleitando» (Jiménez Belmonte 2007: 117). Bien es verdad que pocas miden sus fuerzas y aunque las hallen débiles, no se abstienen de hacer versos y gustan de verlos impresos.

Aunque sus nombres poco o nada nos digan, «el nombre se convierte en presencia, y la nómina, en incuestionable realidad, cuyo número es un argumento más de su relevancia social y de las relaciones de 'socorros mutuos'" (Ruiz Pérez 2010: 24). Tomemos como ejemplo la lista de mujeres participantes en la Palestra numerosa austriaca: Ana Francisca Abarca de Bolea, Ana Paciencia Ruiz Urriés Castilla, Ángela Rodas, Gerónima Gurpide, Gerónima Zaporta, Isabel Peralta, Isabel Rodas Araiz, Isabel Luisa Fernández, Jacinta Sayas Pedroso, Josepha Sayas Pedroso, Juana Sierra, Leonor Garcés Mendoza, Luisa Tucar, 
Madalena Sánchez Sierra, Margarita Villanueva, María Fernández, María Figuerola, María Nieto de Aragón, Serafina Domenec, Teresa Abarca y Teresa Figuera Fernández Moros. En esta nómina sólo identificamos claramente a Ana Francisca Abarca de Bolea, religiosa bernarda en el convento de Casbas (Huesca) y tía del Marqués de Torres, organizador del certamen. Ana Francisca Abarca es, sin duda, la poeta más relevante e importante de todo el grupo. Ya había probado fortuna en un certamen poético anterior, en el de las exequias por Baltasar Carlos (1646), organizado por Uztarroz (1646), con quien mantiene una amistosa relación así como con el círculo de Lastanosa ${ }^{13}$. El certamen es para ella el mejor medio para salir a la palestra pública, pues encuentra en el parentesco una justificación en el caso de que realmente la necesitara. Del convento de Casbas, procede también su compañera Ana Paciencia Ruiz Urriés de Castilla. Por el epígrafe que introduce la composición conocemos que otras dos monjas provienen de Valencia: Serafina Domenec y María Figuerola. Nada sabemos de las religiosas Luisa Tucar y de Teresa Abarca. De una comunidad paraconventual como es el Colegio de las Vírgenes de Zaragoza acude Isabel de Rodas Araiz, autora de un interesante romance burlesco en sayagués con rasgos aragoneses (Vázquez Obrador 1988).

El resto son mujeres laicas, como la madrileña María Nieto de Aragón, discípula de Uztarroz e invitada ex profeso por el propio Marqués, según consta en una de las cartas conservadas. Josefa de Sayas y Pedroso y Jacinta de Sayas y Pedroso posiblemente sean hermanas y sobrinas del poeta y cronista Francisco Diego de Sayas, quien también participa en el certamen y es autor del Discurso sobre la poesía aragonesa, en la edición de las obras del canónigo Martín Miguel Navarro ${ }^{14}$. Quizá Gerónima Zaporta sea la viuda de D. Alonso Funes de Villalpando, de la casa de los Condes de Atarés, fundadora de la Cartuja de la Concepción de Zaragoza, fallecida, según Latassa, en 1659. Teresa de la Figuera Fernández de Moros está vinculada al círculo de Francisco de la Torre y Sevil, en concreto al enclave de Tortosa y Morella ${ }^{15}$. De Margarita Villanueva, alabada por Juan de Moncayo en el Poema de Atalanta (1656, canto V, estrofa 24, p. 110), nada sabemos como tampoco del resto.

A falta de identificaciones más precisas, se puede decir que el grupo está formado por mujeres emparentadas con la nobleza y en su mayor parte pertenecientes al grupo ciudadano, a la élite ciudadana, como venía siendo

13. Para la obra de de Ana Francisca Abarca de Bolea y María Nieto remito a la base de datos BIESES y, en concreto, a los estudios de $\mathrm{M}^{\mathrm{a}}$ de los Ángeles Campo Guiral, Nieves Romero y $M^{a}$ Carmen Marín allí reseñados.

14. Para la vida de Francisco Diego de Sayas, véase Zaragoza Ayarza (2009). El poeta y cronista es el padre de Ana María de Sayas y Pedroso, monja profesa en el convento de Trasobares, a la que compuso unos villancicos para su toma de velo (1644). La religiosa hereda también la afición por la poesía y escribe unos versos para el Entretenimiento de las Musas.

15. A dicho círculo pertenece también Gaspar de la Figuera (participante en el certamen sobre Baltasar Carlos, 1646), Juan Francisco Ram, Francisco de la Figuera, Francesc-Ramon Sans, Lluís de Montsuar, Diego de la Torre y Vicent Bisse. Comenta la filiación aragonesa Enric Querol Coll, Cultura literaria en Tortosa (siglos XVI y XVII), Tesis Doctoral, Universitat Autònoma de Barcelona, 2004, p. 451. 
habitual en certámenes anteriores. Si como individualidades poco nos dicen sus nombres, y es muy difícil devolverlas a la historia con su historia personal, como colectividad, como grupo, el fenómeno no es para echarlo en el olvido. Colectiva e individualmente las mujeres cobran conciencia de autoría, han ganado un espacio literario y, a priori, compiten en pie de igualdad, sin distinción de sexo y condición, pues en una primera instancia los versos anónimos se juzgan por su calidad. En estos certámenes se borran las diferencias de una socialización marcada genéricamente y no hay distinción entre hombres y mujeres. Otro asunto es que el anonimato sea un mero formalismo, que los jueces estén comprados, que los premios estén dados de antemano, como denuncia María Cáncer, y que en las sentencias, a la hora de valorar la poesía femenina, los criterios de juicio sean otros y se estime la belleza de las participantes o se aduzca la cortesía obligada a las damas, aspectos no valorados en los varones.

\section{El ocaso de las Justas aragonesas}

Cuando los certámenes poéticos dejan de celebrarse, las mujeres pierden este espacio literario y con ello la conciencia colectiva e individual de "autoría» con tantos esfuerzos alcanzada. Las versificadoras se quedan huérfanas, sin medios para canalizar sus inquietudes poéticas y para participar visiblemente en la vida cultural y literaria del momento. Es lo que sucede en Aragón a partir de 1650. En el ecuador del siglo, nadie podía pensar que la Palestra iba a ser el cierre de oro de esta tendencia y que con ella se acababa una etapa esplendorosa para la poesía de las mujeres. El panorama con el que nos encontramos a partir de esta fecha es muy diferente (Egido-Laílla 1996; García Aguilar 2009; Bègue 2010).

Aunque se siguen organizando fiestas con motivo de la celebración de exequias, natalicios, bodas o entradas reales así como otras conmemoraciones religiosas y la poesía está presente de forma estática, adornando arcos y túmulos o dentro del aparato emblemático (Serrano 2002), apenas se convocan justas. Hasta 1659, casi diez años después de la publicación de la Palestra, no volvemos a encontrar una nueva, en concreto el «Certamen poético y poesías de los claustros» dispuesto por el convento de San Agustín de Zaragoza para festejar la canonización de Tomás de Villanueva, Arzobispo de Valencia (Paniagua 2005). Da cuenta de ellas Gabriel Manuel Abás y Nicolau, Narraciones de las fiestas en Zaragoza el setiembre de MDCLIX a la canonización de Santo Tomas de Villanueva, Arçobispo de Valencia, del Orden de San Agustin, Zaragoza, Miguel de Luna, 1660, aunque el autor real de la misma fue F. Josef de Enguita. «Por particulares respetos, con mucho desconsuelo de todos los religiosos" (p. 385), parece ser que no se pudo publicar el certamen y al final los versos se imprimieron de forma anónima en este libro.

En 1661, la Universidad de Zaragoza y la Imperial Ciudad de Zaragoza convocan un certamen poético para festejar el nacimiento del Sereníssimo Carlos, Príncipe de las Españas (el futuro rey Carlos II). De este certamen sólo se ha conservado el cartel (Egido 1983b: 57) y el testimonio de Baltasar López 
de Gurrea, conde del Villar, que participó con unas décimas (Gracia Paesa 2006: 82). La beatificación de San Pedro de Arbués (1664) y las canonizaciones de Magdalena de Pazzis y de San Pedro de Alcántara (1669) se celebraron con diferentes fiestas ${ }^{16}$, y es muy probable que se convocaran justas poéticas, pero hoy por hoy sólo contamos con las relaciones en verso de Tafalla Negrete y la perdida de Eugenia Buesso.

En el caso de las exequias por Felipe IV (1665) y las de María Luisa de Borbón (1669), fueron los jesuitas los que se hicieron con los adornos poéticos y quienes solicitaron los poemas que adornaron los escenarios de la fiesta, versos luego recogidos de forma anónima en los impresos. Es el caso de la relación de Juan Antonio Xarque, Augusto llanto, finezas de tierno cariño y reverente amor de la imperial ciudad de Zaragoza, en la muerte del rey su señor Filipe (sic) el grande, quarto de Castilla y tercero de Aragón, Zaragoza, Diego Dormer, 1665. En la misma línea, cuatro años después, hace lo propio Miguel Monreal, Imperiales exequias que en la muerte de la imperial señora y serenisima Reina de España doña María Ana de Austria celebró la imperial ciudad de Zaragoza, Zaragoza, Herederos de Diego Dormer, 1669. Se ha perdido toda huella de autoría y el espíritu de competición. Ya no hay rastro alguno de mujeres. Ninguna poeta concurre tampoco al Torneo poético en loor del ilustrissimo y reverendissimo señor Don Fray Josef de Linas, Arzobispo de Tarragona, Zaragoza, Pascual Bueno, 1695, si bien en este caso podría explicarse por ser un producto interno de los propios alumnos jesuíticos.

Aunque participó en la organización y celebración de diferentes fiestas, la Universidad, otrora tan activa en este campo, no convocó más certámenes hasta 1723, para festejar en este caso la venida de la Virgen a Zaragoza. La relación se publicó en 1724 con el título Aliento fervoroso, respiración festiva, voz sonora con que la Universidad de Zaragoza significó su devoción [...] de la venida de María Nuestra Señora en carne mortal y aparición al apóstol Santiago en la ribera del Ebro, dexando su venerable imagen sobre la sagrada columna, y en ella tan sólo figuran dos mujeres: Doña Juana Chrisóstima Madalena Solís de Ovando, Marquesa de Camarena, y dońa Antonia de Roda, religiosa cisterciense en el Monasterio de Tulebras, de Navarra. En los objetivos de este certamen estaba el evitar la participación de poetas voluntarios. Después de unos ańos esplendorosos para la práctica poética fuera del ámbito privado, se impone una nueva realidad que refrena el amateurismo desatado en la primera mitad de siglo y hace una criba en la proyección pública de los poetas.

16. Nada se dice en la relación de Bartolomé García, Fiestas en Zaragoza de las canonizaciones de... San Pedro de Alcántara y Santa Maria Magdalena de Pazzi, Zaragoza, 1670. Eugenia Buesso compuso una Relación de las fiestas que en la imperial ciudad de Zaragoza se han hecho en la canonización de S. Pedro de Alcántara y Santa María Magdalena de Pazzis, Zaragoza 1669, en folio, hoy desaparecida. 


\section{¿DÓNDE ESTÁN LAS MUJERES POETAS?}

¿Han desaparecido por completo?, ¿dónde se refugian aquellas mujeres con inquietudes poéticas?, ¿`editan en solitario de forma exenta?, ¿en los preliminares de libros?, jacuden y publican en las academias? Volvamos de nuevo la vista a los años inmediatos a la publicación de la Palestra, momento en el que se inicia un periodo de importantes cambios en el mundo poético aragonés, y en concreto en el zaragozano (Egido 1988; Ruiz Pérez 2011). En esta década proliferan en letras de molde las ediciones poéticas de autores concretos en convivencia con señeras antologías.

Por estos años una serie de poetas que concurren a las academias y círculos literarios aragoneses, algunos de los cuales también han frecuentado los certámenes, reúnen sus versos en un poemario y lo dan a la imprenta. Es el caso de Juan de Moncayo (Rimas, Zaragoza, 1652), Alberto Díez y Foncalda (Poesias varias, Zaragoza, 1653), José Navarro (Poesias varias, Zaragoza, 1654, y participante en la Palestra) o Francisco de la Torre (y Sevil) (Entretenimiento de las Musas, Zaragoza, 1654), quien con sólo diecisiete años había concurrido al certamen por Apaolaza (1642). Entre 1652 y 1663 se publican en las prensas zaragozanas diez volúmenes poéticos de autores locales o asentados en la ciudad que revelan un cambio en la práctica poética. Como advierte Ruiz Pérez, «lejos quedan ya los cerrados círculos cortesanos y los gabinetes humanistas, pero también esa otra forma de poesía pública constituida por las academias y sus manifestaciones sociales, en forma de certámenes y justas ligadas a la fiesta» (2011: 89). Evidentemente entre estos diez volúmenes no hay ninguno firmado por mujeres porque de las que han concurrido a las justas ninguna tiene por entonces una obra lo suficientemente amplia como para darla a la imprenta en un libro unitario. Sólo la madrileña María Nieto de Aragón logra imprimir en Madrid sus pliegos y Ana Francisca Abarca de Bolea tardará aún varios años hasta publicar de forma exenta. Ninguna aparece recogida por José Alfay en su famosa antología Poesías varias de grandes ingenios. Recogidas por José Alfay (Zaragoza, Juan de Ibar, 1654), como tampoco en la reedición revisada en 1670 y titulada Delicias de Apolo, recreaciones del Parnaso.

Si la producción de obras líricas de un único autor se duplica en relación con la primera mitad del siglo y la celebración de certámenes comienza a decaer, evidentemente se está imponiendo una nueva fórmula en el mundo editorial poético a la vez que un cambio en la actitud de los poetas. Los poetas ocasionales, los simples aficionados a la versificación, pierden un espacio literario y con ello su voz se acalla; la de las mujeres se silencia de nuevo. El triunfo del libro de poesía sin duda ayuda a desplazar y a arrinconar de algún modo la celebración y publicación de estos certámenes poéticos, costosos por su reparto de premios y por la posterior publicación en libro impreso, en un momento de penuria y de falta de mecenas como Francisco Miravete, Sancho Zapata o don Martín de Agullana que sufraguen los costes del evento. Así las cosas, ¿¿dónde se reacomodan todas estas mujeres con inquietudes poéticas? 
Algunas acuden a certámenes convocados en otras ciudades, como sucede con Sor Teresa Des y Martes y Sor Teresa Ulcina, religiosas bernardas en el convento de Casbas, que concurren al celebrado en Salamanca en 1658 por el nacimiento del príncipe Felipe Próspero (Serrano y Sanz 1975, I: 344 y $550-$ 551); otras, las más privilegiadas, por amistad encuentran alojamiento en los preliminares de libros de poesía. Tres religiosas figuran en los paratextos del Entretenimiento de las Musas de Francisco de la Torre Sevil: Ana Francisca Abarca de Bolea, a quien el tortosino le devolverá los elogios en unos encomiásticos versos para sus Catorce Vidas de santas de la orden del Cister (Zaragoza, 1655); Ana María de Sayas Rabaneda, hija del cronista y poeta ya citado Francisco Diego de Sayas Ravaneda, asiduo en los certámenes poéticos, y sor Cecilia Bruna, de la que no tengo noticias. Los versos de estas religiosas se confunden con los de Juan de Moncayo, Manuel de Salinas o el citado Francisco Diego de Sayas y ligan la obra, el Entretenimiento de las Musas, al enclave aragonés. Si para ellas es un reconocimiento público el poder comparecer junto a otros poetas consagrados, para Francisco de la Torre Sevil es un medio de demostrar sus lazos personales con los más variados sectores de la sociedad aragonesa ${ }^{17}$.

Un año después de la publicación de la baraja poética, Juan de Moncayo conformará los preliminares de su Poema trágico de Atalanta (Zaragoza, Diego Dormer, 1656) con versos exclusivamente femeninos, si bien ninguna de las firmantes ha participado en las justas aragonesas del momento y sus nombres dan cuenta más de las amistades y de las relaciones del poeta en la corte madrileña que en la aragonesa, aunque luego en el poema elogie a algunas de las damas que habían acudido a varios de los certámenes comentados.

Fuera de este marco paratextual poco acomodo encuentran las versificadoras para demostrar su arte. Las ocasiones son contadas. Para celebrar la figura del carmelita Raimundo Lumbier se invita a los mejores ingenios de España a cantar sus glorias y los versos reunidos se recogen en la tercera parte del volumen dedicado a su figura, publicado en $1687^{18}$. Entre estos versos aparecen unos de Cecilia Villanueva, "colegial del religiosísimo colegio de las Vírgenes», que también escribe unas décimas en la Lira poética (1688) de Vicente Sánchez (Duce 2003: 29).

Desde luego los certámenes y justas de las academias aragonesas están vedados para ellas, pues son convocatorias privadas propias de y para los académicos ${ }^{19}$.

17. Curiosamente, cuando La Torre y Sevil traslade su residencia a Valencia y esté detrás de los certámenes allí organizados $(1655,1667,1668)$ (Mas i Usó 1991), ninguna mujer acudirá a ellos.

18. Joseph Boneta, Vida exemplar del Venerable Padre M. Fr. Raymundo Lumbier de el Orden de N. S. del Carmen de la antigua observancia, Zaragoza, por Domingo Gascón, 1687, pp. 163284. Se ha perdido el espíritu de competición.

19. Muchas de las reuniones las dedicaban a certámenes poéticos, aunque en las primeras dominaba más la prosa. Para las academias aragonesas, véase Sánchez (1960), King (1963), Egido (1984) y Duce García (2009). En relación con la Academia Pítima contra la ociosidad, fundada en 1608 por Gaspar de Galcerán de Castro Pinós, conde de Guimerá, junto a su esposa Isabel Inés de Eril, la Condesa de Guimerá y su madre, la Condesa de Eril, firmaron los estatutos y acudieron a las sesiones, pero no se conserva trabajo suyo presentado a la Academia. 
La academia de los Anhelantes de Andrés Uztarroz ${ }^{20}$, tan afecto a la escritura femenina, no da cabida a ninguna mujer. Las academias del conde de Lemos y del conde de Andrade, en las que se dan cita también muchos de los poetas que venían participando en las diferentes justas antes comentadas, son cotos cerrados y sólo algunas privilegiadas podrían tener acceso como espectadoras o mironas, pero no tenemos noticias como creadoras ${ }^{21}$. Por los vejámenes de Alberto Díez y Foncalda (Poesías varias, 1653) y José Navarro (Poesías varias, 1654) sobre la academia del conde de Lemos, sabemos que la mujer era tema de academia pero no académica ${ }^{22}$. Lo mismo vale decir, en los años siguientes, de la academia del Príncipe de Esquilache (virrey de Aragón), conocida por el vejamen de Vicente Sánchez en su Lira poética (Zaragoza, 1688), o de la academia de los Misteriosos, de la que da cuenta José de Tafalla y Negrete en sus Poesías Varias (Zaragoza, 1706). La situación aragonesa en este sentido dista poco de la madrileńa o de la valenciana, donde las mujeres están prácticamente ausentes de las academias, aunque haya casos excepcionales como el de la castellonense María Egual, marquesa de Castellfort, en cuya casa valenciana parece ser que se reunían a comienzos del siglo XVIII (1705) algunos literatos (Mas i Usó 1999: 379-400; Mas-Vellón 1997). No entro, sin embargo, en las academias del siglo XVIII (Palacios Fernández 2002).

Las autoras con obra poética exenta son muy escasas y a excepción de Eugenia Buesso, con tres pliegos poéticos conocidos, se circunscriben al ámbito religioso. El caso más relevante es el de Mariana Sallent, natural de Borja y monja en el convento de Santa Clara, quien publica su Vida de la seráfica Madre Santa Clara en verso en Zaragoza, en 1700, reeditada después en Valencia (1703) y en Lima (1717) (Santos Aramburo 2002). Detrás de la publicación de esta hagiografía en verso se encuentra su hermano Francisco Antonio Sallent, doctor en leyes por la Universidad de Zaragoza (1674) y obispo auxiliar de Valencia. A su prestigio y relaciones personales se debe, sin duda, el elenco de poetas que elogian la figura de Mariana Sallent en los preliminares de su

20. Ningún rastro de participación femenina he hallado en las actividades de la Academia de los Anhelantes (1628-1653), fundada por Uztarroz, buen conocedor de este tipo de certámenes y de la poesía femenina. No participan mujeres en el certamen poético organizado por la academia en honor de Santo Domingo de Val 1634 (véase Historia de Santo Domingo de Val, Zaragoza, 1643, cap. XIV).

21. No es el caso de María de Zayas en Barcelona (Brown 1993), citada por el poeta barcelonés Francesc Fontanella en un vexamen de la Academia de Santo Tomás de Aquino (fechado el 15 de marzo de 1643), a cuyas reuniones y certámenes también asistían mujeres (Brown 1987:194).

22. Alberto Díez y Foncalda, Poesías varias. Primera parte, pp. 59-72; Iosef Navarro, Poesías varias, pp. 53-68; pp. 141-157. En la academia del conde de Lemos, fue asunto «Da la razón por qué las feas son entendidas y mejor para queridas» (Alberto Díez y Foncalda, p. 160); "A una muger que nunca se santiaguaba y le cruzaron la cara» (José Navarro, p. 176) y «A una dama que tenía muy pequeño cuerpo y muy grandes ojos» (José Navarro, p. 195). En las 33 academias de la segunda mitad del siglo XVII analizadas por Bègue (2007), ninguna de ellas aragonesa, sólo en tres figuran mujeres como poetas o académicas («una dama», Josefa Bernarda de Aragón, Sebastiana Cruzate e Isabel de Tapia). En la gaditana del Marqués de Jamaica (1672), los poetas hablan en nombre de las damas para felicitar a Mariana de Austria. 
libro. Años antes, Sor Gerónima de la Ascensión, religiosa del convento de Santa Clara de Tudela, verá publicados póstumamente sus versos como parte del discurso de su vida en los Exercicios espirituales (Zaragoza, 1661, cap. XXIX, fols. 150v-157v), lo mismo que Sor María Francisca de S. Antonio, natural de Alcañiz, religiosa en el convento de la Concepción de las Cuevas de Cañarte (Teruel), cuyos poemas aparecen impresos en el libro de su vida escrito por Roque Alberto Faci, titulado Hermosa azuzena y estrella plantada y fixa en el suelo y cielo del convento del Orden de la Purísima Concepción de la Villa de las Cuevas de Cañarte, en el Reino de Aragón, Zaragoza, 1737. Ana Francisca Abarca de Bolea, en cambio, los inserta en su Vigilia y Octavario de San Juan Baptista, publicado en 1679, cuando la autora cuenta con 77 ańos. Los ciento nueve poemas incluidos son la obra poética de toda su vida ${ }^{23}$.

Al decaer de forma tan acusada la convocatoria de certámenes, la presencia femenina en los ámbitos intelectuales públicos desaparece prácticamente de golpe y deja un vacío difícil de cubrir, pues no es fácil la relación de la mujer, en este caso de las versificadoras, con el libro impreso. Los libros de certámenes se estampan para inmortalizar el evento histórico celebrado, pero también para que perviva la memoria de los autores. Así se declara en el prólogo del libro que recoge el certamen poético por la traslación de la reliquia de San Ramón Nonat (Zaragoza, 1618), dedicado a Luisa de Padilla, condesa de Aranda, donde se justifica la impresión para cumplir con todos: «Con el Santo, a quien damos lo que es suyo; con los devotos, que tendrán luz para mayor patrocinio y con los autores, que tendrán en más la corta estimación de sus obras ya estampadas para gloriosa duración de su memoria que tuvieran el premio, cuya gloria solo dura el día que lo reciben». La impresión de sus versos se valoraba tanto o más que los premios porque no era fácil alcanzarla y más para las mujeres. Aunque muchas de estas poetas aficionadas (ocasionales) pertenecientes a la nobleza y a la élite ciudadana sigan manteniendo una red de relaciones personales de amistad o parentesco con los poetas del momento, estas conexiones ya no bastan para salir ellas a la palestra y formar parte de la república de los poetas. La pérdida de este espacio público de sociabilidad literaria las relega, en el mejor de los casos, a su condición lectora y si escriben lo harán en la intimidad o para un círculo muy cerrado de allegados donde sus versos correrán de forma manuscrita. Andando el tiempo, a mediados de la nueva centuria, las tertulias y la prensa les brindarán un nuevo cauce de comunicación para demostrar sus habilidades como poetas ${ }^{24}$, pero en ese lapso de tiempo de casi un siglo se han perdido las voces de muchas poetas aficionadas que hicieron de la poesía un pasatiempo culto y delicado con el que participaron en pie de igualdad en la vida ciudadana. Como los poetas, también ellas fueron llamadas para cantar a

23. Ana Francisca Abarca de Bolea, Vigilia y Octavario, ed. Ma Ángeles Campo Guiral, Huesca, Instituto de Estudios Altoaragoneses, 1993, p. CIII.

24. Además de promocionar determinadas figuras y obras, como sucede con la andaluza Teresa Guerra, la prensa también acoge sus creaciones, entre ellas las poéticas, pero eso será ya en la segunda mitad del XVIII (Palacios 2002; Urzainqui 2002). 
sus reyes, a sus santos o a sus conciudadanos y acudieron a la cita con sus versos. Su entusiasta respuesta en tierras aragonesas demuestra que existía un interés por la poesía entre las mujeres y una voluntad de integrarse a través de ella en la vida pública y en la actividad cultural del momento, de perpetuar la memoria de la historia de la que ellas también formaban parte.

\section{Bibliografía}

Alvar Elena, «Exequias y certamen poético por Margarita de Austria (Zaragoza, 1612)», AFA, XXVI-XXVII, 1980, pp. 225-389.

Baranda Nieves, Cortejo a lo prohibido. Lectoras y escritoras en la España moderna, Madrid, Arco/Libros, 2005.

Bègue Alain, Las academias literarias en la segunda mitad del siglo XVII. catálogo descriptivo de los impresos castellanos de la Biblioteca Nacional de Madrid, Madrid, Biblioteca Nacional, 2007.

— "Albores de un tiempo nuevo: la escritura poética de entre siglos (XVII-XVIII)», en La luz de la razón. Literatura y Cultura del siglo XVIII. A la memoria de Ernest Lluch, eds. Aurora Egido y José Enrique Laplana, Zaragoza, Institución «Fernando el Católico», 2010, pp. 37-69.

Brown Kenneth, "Context i text del Vexamen d'Acadèmia de Francesc Fontanella", Llengua \& Literatura, 2, 1987, pp. 173-252.

— «María de Zayas y Sotomayor: escribiendo poesía en Barcelona en época de guerra (1643)», Dicenda. Cuadernos de Filología Hispánica, 11, 1993, pp. 355-360.

Cuevas Subías Pablo, "Las humanidades en Huesca en tiempos de Lastanosa», en Mecenazgo y Humanidades en tiempos de Lastanosa. Homenaje a Domingo Ynduráin, eds. Aurora Egido y José Enrique Laplana, Zaragoza, Institución «Fernando el Católico», 2008, pp. 135-159.

Duce García Jesús, ed., Vicente Sánchez, Lira poética, Zaragoza, Prensas Universitarias de Zaragoza, 2003, 2 vols.

— «Las academias literarias aragonesas del siglo XVII», Ágora, 4, 2009, pp. 12-18.

Egido; Aurora, "Los modelos en las justas poéticas aragonesas del siglo XVII», RFE, 60, 1978-1980, pp. 159-171.

— «Cartel de un certamen poético de los jesuitas en la ciudad de Tarazona (1622)», AFA, XXXIV-XXXV, 1983a, pp. 103-120.

— "Certámenes poéticos y arte efímero en la Universidad de Zaragoza (siglos XVI y XVII)», en Cinco estudios humanisticos para la Universidad de Zaragoza en su centenario IV, Zaragoza, Caja de Ahorros de la Inmaculada, 1983b, pp. 9-78.

— "Las academias literarias de Zaragoza en el siglo XVII», en La literatura en Aragón, Zaragoza, Caja de Ahorros y Monte de Piedad de Zaragoza, Aragón y Rioja, 1984, pp. 101-28.

— «Una introducción a la poesía y a las academias literarias del siglo XVII», Estudios humanisticos filologia (Universidad de León), 6, 1984, pp. 9-26.

Egido Aurora y Ángel San Vicente, Certamen poético que la Universidad de Zaragoza consagró a D. Pedro de Apaolaza, Zaragoza, Institución «Fernando el Católico», 1986.

— «La literatura en Aragón: de los orígenes a finales del siglo XVIII», en Enciclopedia temática de Aragón. T. 7, Literatura, Zaragoza, Moncayo, 1988, pp. 97-225. 
— «Las cofradías zaragozanas del siglo XVII y su proyección literaria (con un escolio al Quijote)", en Les parentés fictives en Espagne (XVIe-XVII siècles), París, Publications de la Sorbonne, 1988, pp. 145-158.

Egido Aurora y Luis Sánchez Laílla, "Certámenes literarios aragoneses del Siglo de Oro», en Fiestas públicas en Aragón en la Edad Moderna. VIII Muestra de Documentación Histórica Aragonesa, Zaragoza, Diputación General de Aragón, 1996, pp. 47-55.

— «Florilegio poético de la Universidad de Zaragoza en la muerte de su fundador, Pedro Cerbuna (1597)", en Memorial de la Universidad de Zaragoza por Pedro Cerbuna de Fonz en el IV centenario de su muerte 1597-1997, eds. Ángel San Vicente Pino y Eliseo Serrano Martín, Zaragoza, Universidad de Zaragoza, 1997, pp. 159-172.

- "Justas poéticas marianas en el Barroco aragonés», en María, fiel al espíritu. Su iconografía en Aragón de la Edad Media al Barroco, del 8 de septiembre al 10 de noviembre de 1998, Zaragoza, Museo "Camón Aznar», 1998, pp. 63-75.

— «La Nobleza virtuosa de la Condesa de Aranda, Luisa de Padilla, amiga de Gracián», AFA, LIV-IV, 1998, pp. 9-41.

García Aguilar Ignacio, ed., Tras el canon. La poesía del Barroco tardio, Vigo, Editorial Academia del Hispanismo, 2009.

Gracia Paesa Teresa, Las «Clases Poéticas» de Baltasar López de Gurrea, Conde del Villar. Estudio y edición, Zaragoza, tesis doctoral inédita, 2006.

Jiménez Belmonte Javier, Las obras en verso del Príncipe de Esquilache: amateurismo y conciencia literaria, Woodbridge, Tamesis, 2007.

King Willard F., Prosa novelistica y academias literarias en el siglo XVII, Madrid, Anejos del Boletín de la Real Academia, 1963.

Latassa y Ortín Félix, Biblioteca nueva de los escritores aragoneses, III, ed. Genaro Lamarca Langa, Zaragoza, Real Sociedad Económica Aragonesa de Amigos del País, Ibercaja, 2004.

Mas i Usó Pasqual, Justas, academias y convocatorias literarias en la Valencia Barroca (1591-1705): teoría y práctica de una convención, tesis doctoral, edición digital, Biblioteca virtual Miguel de Cervantes, 1991.

- Academias y justas literarias en la Valencia Barroca, Kassel, Reichenberger, 1996.

Mas i Usó Pasqual y Javier Vellón, La literatura Barroca en Castellón. María Egual (1644-1735). Obra completa, Castelló, Sociedad Castellonense de Cultura, 1997.

Mas i Usó Pasqual, Academias valencianas del Barroco. Descripción y diccionario de poetas, Kassel, Reichenberger, 1999.

Mateos Royo José Antonio, «La ciudad con el rey: municipio, monarquía y ritual cívico en Zaragoza bajo Felipe III (1598-1621)», Revista Pedralbes, 21, 2001, pp. 137-164.

Oltra Tomás José Miguel, «Un mundo para un certamen: aproximación a la Palestra numerosa austriaca de Huesca (1650)", en Actas del I y II Curso en torno a Lastanosa. La cultura del Barroco. Los jardines: arquitectura, simbolismo y literatura, ed. José Enrique Laplana Gil, Huesca, Instituto de Estudios Altoaragoneses, 2000, pp. 93110.

Osuna Inmaculada, "Justas poéticas en Granada en el siglo XVII: materiales para su estudio", Criticón, 90, 2004, pp. 35-77.

Palacios Fernández Emilio, «El Parnaso poético femenino en el siglo XVIII: escritoras neoclásicas», en Las mujeres escritoras en la Historia de la Literatura Española, coords. Lucía Montejo Gurruchaga y Nieves Baranda Leturio, Madrid, UNED, 2002, pp. 85-121.

- La mujer y las letras en la España del siglo XVIII, Madrid, Laberinto, 2002. 
Paniagua Ricardo, «Fiestas celebradas en Zaragoza (1659) con motivo de la canonización de Santo Tomás de Villanueva», Archivo Agustiniano, 89, 2005, pp. 115-144.

Pérez Gómez Antonio y Manuel Muñoz Cortés, Justas y certámenes poéticos en Murcia (1600-1635), Murcia, [Academia de Alfonso X el Sabio], 3 vols., 1958-1959.

Pérez Lasheras Antonio, "Introducción a la poesía aragonesa de los Siglos de Oro», en Literatura y territorio. Hacia una geografía de la creación literaria en los Siglos de Oro, ed. Andrés Sánchez Robayna, Las Palmas de Gran Canaria, Academia Canaria de la Historia, 2010, pp. 227-244.

Querol Coll Enric, Cultura literaria en Tortosa (siglos XVI y XVII), Tesis Doctoral, Universitat Autònoma de Barcelona, 2004.

Riquer Martín de, «Don Martín de Agullana y el torneo poético de Gerona», en Homenaje a José Manuel Blecua, ofrecido por sus discípulos, colegas y amigos, Madrid, Gredos, 1983, pp. 533-564.

Rossich Albert, "Els certàmens literaris a Barcelona, segles XIV-XVIII», Barcelona Quaderns d'Historia, 9, 2005, pp. 83-108.

Ruiz Pérez Pedro, «La escala del Parnaso», en El parnaso versificado. La construcción de la república de los poetas en los Siglos de Oro, Madrid, Abada Editores, 2010, pp. 5-339.

— «La edición zaragozana a mediados del siglo XVII y la sistematización del libro de poesía», en El libro de poesía (1650-1750): del texto al lector, no monográfico del Bulletin Hispanique, 113/1, 2011, pp. 69-101.

Salas Auséns José Antonio, Historia de Zaragoza en el siglo XVII, Zaragoza, Ayuntamiento de Zaragoza, 1998.

Sánchez José, Academias literarias del siglo de oro español, Madrid, Gredos, 1960.

Santa Teresa Fr. Higinio de, ed., Fr. Jerónimo de San José, Genio de la Historia. Ensayo Bio-Bibliográfico, Vitoria, Ediciones «El Carmen», 1957.

Santos Aramburo Ana, «Una poetisa borjana del siglo XVII: Sor María Sallent, religiosa franciscana clarisa del convento de Santa Clara», Cuadernos de Estudios Borjanos, XLV, 2002, pp. 71-94.

Serrano Martín Eliseo, «Felipe V en Zaragoza: las celebraciones festivas», en Felipe V de Borbón, 1701-1746. Actas del Congreso de San Fernando (Cádiz), del 27 de noviembre al 1 de diciembre de 2000, coord. José Luis Pereira Iglesias, Córdoba, Servicio de Publicaciones Universidad de Córdoba, 2002, pp. 319-340.

- «Fiestas, celebraciones religiosas y políticas en la España de la Edad Moderna. Algunos ejemplos aragoneses», Memoria Ecclesiae, XXXIV, 2010, pp. 105-141.

Serrano y Sanz Manuel, Apuntes para una biblioteca de escritoras españolas. Desde el año 1401 al 1833, Madrid, Atlas; $1^{\text {a }}$ ed. 1903; 1975.

Vázquez Obrador Jesús, «Poesías en aragonés de la Palestra numerosa austriaca (Huesca, 1650): estudio lingüístico», Alazet, 0, 1988, pp. 153-190.

Solera López Rus, ed., Jerónimo de Cáncer y Velasco, Obras varias, Zaragoza, Prensas Universitarias de Zaragoza, 2005.

Urzainqui Inmaculada, "Los espacios de la mujer en la prensa del siglo XVIII», en Del periódico a la sociedad de la información, I, eds. Celso Almuiña y Eduardo Sotillos, Madrid, Sociedad Estatal España Nuevo Milenio, 2002, pp. 53-79.

Zaragoza Ayarza Francisco, "Antecedentes familiares de Francisco Diego de Sayas Rabanera y Ortubia, historiador de la Almunia de Doña Godina (1598-1678)», Rolde, 129, 2009, pp. 6-11. 


\section{Apéndice. Justas poéticas celebradas en Aragón EN LA PRIMERA MITAD DEL SIGLO XVII}

1608. Certamen en honor de Jerónimo Javierre (sólo se conserva el cartel, BNM, ms. 9572). (Egido 1983b: 33-35).

1612. Francisco de Diego Ainsa y de Iriarte, Translación de las reliquias del Glorioso Pontifice S. Orencio, Huesca: Juan Pérez de Valdivielso. (4 mujeres).

1612. Relación de las esequias que hizo la Imperial ciudad de Çaragoça a la muerte de la serenissima Reyna Margarita de Austria nuestra señora. (Alvar 1980). (5 mujeres).

1615. Luis Díez de Aux, Retrato de las Fiestas que a la Beatificacion de la Bienaventurada Virgen y Madre Santa Teresa de Jesus, Renovadora de la Religion Primitiva del Carmelo, hizo, asssi Eclesiasticas como Militares y Poeticas la Imperial Ciudad de Zaragoça, Zaragoza: Juan de la Naja Quartanet. (13 mujeres).

1618. Pedro Martín, Certamen poetico a las fiestas de la translación de la reliquia de San Ramon Nonat. Zaragoza: Juan de Lanaja y Quartanet. (Incluye también materiales de un certamen de Daroca sobre el mismo tema). (16 mujeres).

1619. Luis Díez de Aux, Compendio de las fiestas que ha celebrado la imperial ciudad de Çaragoça por aver promovido la Magestad Cathólica del Rey nuestro señor Filipo Tercero [...] al Illustríssimo señor don Fray Luis de Aliaga su confessor, y de su Real Consejo de Estado, en el oficio y cargo supremo de Inquisidor General de España. Zaragoça: Juan de Lanaja y Quartanet. (20 mujeres).

1619. Sancho Zapata, Iusta poética en defensa de la pureça de la Inmaculada Conçepcion de la Virgen Sanctissima mantenida y premiada por D. Sancho Çapata, su devoto y esclavo. Zaragoça: Diego la Torre, 1619. (31 mujeres).

1622. Certamen poético que un cavallero de la insigne ciudad de Tarazona muy devoto de los gloriosos santos Ignacio y Xavier y de la compañia de Jesús propone a todos los buenos ingenios para las fiestas de sus canonizaciones. (Egido 1983a)

1623. Juan Bautista Felices de Cáceres, El cavallero de Ávila por la Santa Madre Teresa de Jesús [...] Con un certamen poético por la cofradía de la sangre de Christo, acción del mismo cavallero. Zaragoza: Diego Latorre. (14 mujeres).

1629. Juan Bautista Felices de Cáceres, Justa poética por la Virgen Santíssima del Pilar. Celebración de su insigne cofradia. Çaragoça: Diego La Torre. (10 mujeres). 
1643. Juan Francisco Andrés de Uztarroz, El certamen poetico que la Universidad de Zaragoza consagro a la munificencia y liberalidad del Ilustrisimo y Reverendisimo Señor Arzobispo don Pedro de Apaolaza. Manuscrito. (Egido-San Vicente 1986). (9 mujeres).

1644. Juan Francisco Andrés de Uztarroz, Certamen poético de nuestra señora de Cogullada, ilustrado con una breve chronología de las imágines aparecidas de la Virgen Sacratíssima en el reino de Aragón. Zaragoza: Hospital Real y General de Nuestra Señora de Gracia. (14 mujeres).

1646. Juan Francisco Andrés de Uztarroz, Contienda poetica que la imperial ciudad de Zaragoza propuso a los ingenios españoles en el fallecimiento de Serenissimo Señor don Balthasar Carlos de Austria, Principe de las Españas. Çaragoça: Diego Dormer. (14 mujeres).

1650. Ioseph Félix de Amada, Certamen literario que el Illustrissimo Señor Marqués de Torres propuso a los ingenios españoles en la ciudad de Huesca al glorioso tálamo de los invictos y católicos reyes de las Españas, Philipo Quarto el grande y Mariana de Austria la esclarecida. Huesca: Iuan Francisco de Larumbe. (21 mujeres). 